\title{
Effects of climate variability and climate change on the fishing conditions for grey mullet (Mugil cephalus L.) in the Taiwan Strait
}

\author{
Kuo-Wei Lan • Ming-An Lee • Chang Ik Zhang • \\ Pei-Yuan Wang • Long-Jing Wu $\cdot$ Kuo-Tien Lee
}

Received: 29 August 2013 / Accepted: 11 July 2014 / Published online: 27 July 2014

(C) The Author(s) 2014. This article is published with open access at Springerlink.com

\begin{abstract}
Grey mullet (Mugil cephalus L.) is one of the most important commercial species of fish in the coastal fisheries of Taiwan. In this study, we analyzed the long-term (1967-2009) records of grey mullet catch per unit effort (CPUE) in the Taiwan Strait (TS) to investigate the influences of climatic indices on the annual catch of grey mullet at multiple timescales. A wavelet analysis revealed that variations in climatic indices, namely the Pacific Decadal Oscillation (PDO), the Oceanic Niño Index, and sea surface temperatures (SSTs) might have affected the abundance and migration behavior of grey mullet in the TS in winter. The CPUE of grey mullet showed significant high correspondence with the annual PDO index $\left(R^{2}=0.82, p<0.01\right)$. The results suggested that the PDO affects the migration of grey mullet, but that increases in SSTs are a more important influence on the decreased catches of grey mullet after 1980. Mean SSTs increased $1.01{ }^{\circ} \mathrm{C}$ at the Chang-Yuen Rise in the TS from 1984 to 2009 . The $20{ }^{\circ} \mathrm{C}$ isotherms in the TS in the winter also shifted from $23-24^{\circ} \mathrm{N}$ in $1958-1978$ to north of $25^{\circ} \mathrm{N}$
\end{abstract}

K.-W. Lan $\cdot$ M.-A. Lee $(\bowtie) \cdot$ P.-Y. Wang $\cdot$ K.-T. Lee

Department of Environmental Biology Fisheries Science, National Taiwan Ocean University,

2 Pei-Ning Rd., Keelung 20224, Taiwan, Republic of China

e-mail: malee@mail.ntou.edu.tw

K.-W. Lan • M.-A. Lee

Center of Excellence for Oceans, National Taiwan Ocean University, 2 Pei-Ning Rd., Keelung 20224,

Taiwan, Republic of China

C. I. Zhang

Department of Marine Production System Management, Pukyong National University, 559-1, Daeyeon,

Busan 608-737, South Korea

L.-J. Wu

Fisheries Research Institute, COA, Taiwan, Coastal and Offshore Resources Research Center,

1-1 North 1 st Road, Kaohsiung 80672, Taiwan, Republic of China

M.-A. Lee

Taiwan Group On Earth Observations, 13F-3, No.32, Gaotie 2nd Road, Hsinchu 30274, Taiwan, Republic of China 
after 1998. The fishing grounds of grey mullet also shifted to the north following changes in the $20{ }^{\circ} \mathrm{C}$ isotherm in the TS.

\section{Introduction}

The grey mullet (Mugil cephalus L.) is a cosmopolitan species that is distributed in tropical and temperate zones at latitudes $42^{\circ} \mathrm{N}-42^{\circ} \mathrm{S}$ (Thomson 1963). Shen et al. (2011) identified three cryptic species of M. cephalus in the northwestern Pacific Ocean and indicated that the distributional range of these species appeared to be governed primarily by three major ocean current systems, the South China Current, North China Coastal Current (NCCC), and Kuroshio Current. Previous studies have reported that the spawning and nursery grounds of the regional group of grey mullet affected by the NCCC are distributed in the coastal waters of the southeastern Taiwan Strait (TS). The feeding grounds of juveniles and adults are located in the coastal and estuarine waters of China at $25^{\circ} \mathrm{N}-30^{\circ} \mathrm{N}$ (Fig. 1) (Tung 1981; Huang and Su 1986). Tung (1981) discovered that the grey mullet lives in the coastal waters of China and that it matures at the age of 3-4 y. It migrates to the coastal waters of the southeastern TS for spawning in the cold NCCC in winter.

Since 1958, the catch of grey mullet in the coastal fishery of Taiwan has fluctuated widely, exhibiting peaks of 2.54 million fish in 1980 and as little as 0.2 million fish in 2000-2004

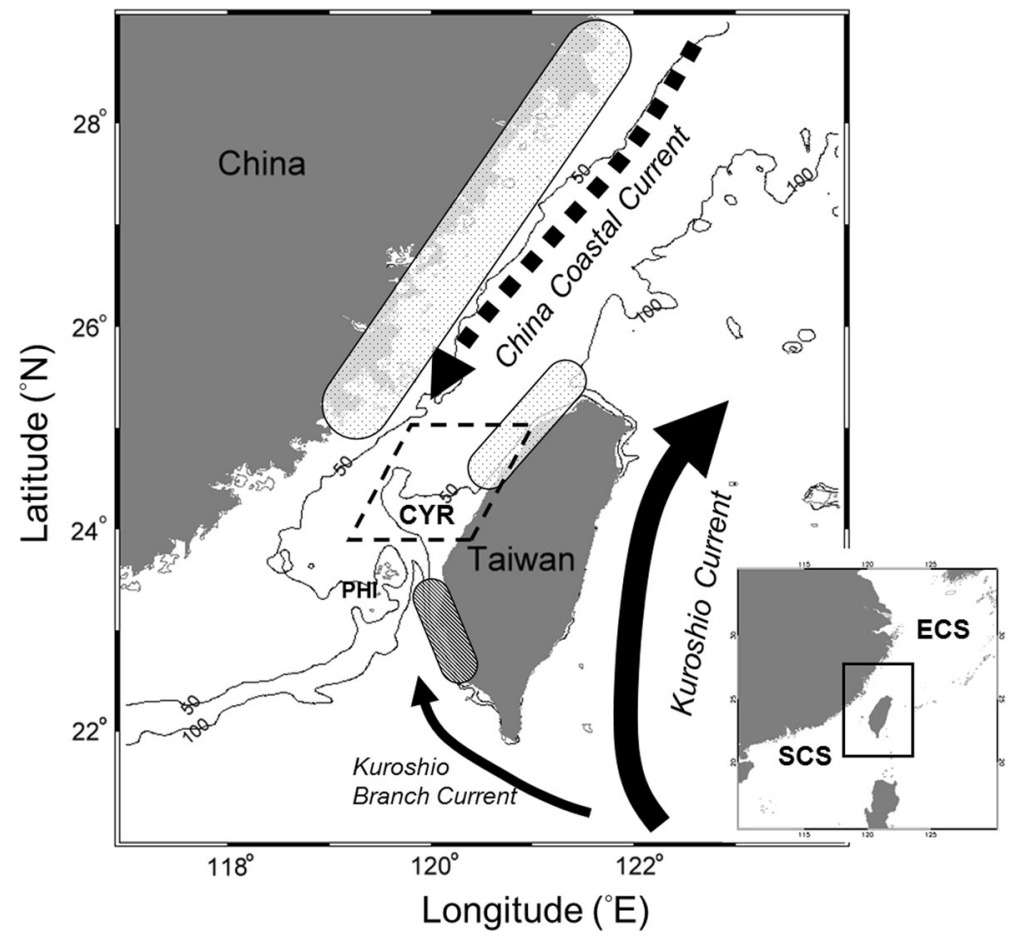

Fig. 1 Feeding ground (dos) and suspected spawning ground (parallel lines) of grey mullet in the Taiwan Strait and China in relation to oceanic currents of the North China Coastal Current (broken line with arrows) and Kuroshio Current (solid line with arrows) during the fishing season (late November to early February). Variations in the sea surface temperature at the Chang-Yuen Rise (CTR, black dashed box in Fig. 1) were used to examine variations in the North China Coastal Current in the Taiwan Strait following Tzeng et al. (2012b). ECS, East China Sea; SCS, South China Sea 
(Fig. 2a). Recently, the population of grey mullet has rapidly declined, causing fishermen to reduce personnel expenses and production costs. Fishermen have gradually changed their fishing gear from purse seines to drift gill nets and stopped using purse seines since 2003 (Fig. 2b). Two major factors are believed to have affected the grey mullet resource in recent years. First, the sharp decline in Taiwanese catches has been attributed to an expansion in the sizes of the fishing fleets from Mainland China targeting the grey mullet (Huang et al. 2005; Hung and Shaw 2006). Because of their geographical advantage, the fishermen in Mainland China harvest fish at the source from where the grey mullet starts the southward migration, causing the collapse of the grey mullet fishery in Taiwan (Hung and Shaw 2006). The lack of an effective cooperative fishery management agency and the strong demand for grey mullet in Taiwan have both accelerated the depletion of the grey mullet stock and have had a negative effect on the welfare of the people in Taiwan (Hung and Shaw 2006). In addition, overfishing may be another reason that explains the decline in the annual catch in the 1980s (Tung 1981, Huang et al. 2005). Catches of grey mullet in the fishing grounds in the TS are composed of 2- to 4-y-old fish, predominantly fish aged 3 to 4 y (Tung 1981, Huang and $\mathrm{Su}$ 1986). Huang et al. (2005) explored the age composition of grey mullet caught by Taiwanese fishing boats in 2004 and determined that the fish were predominantly aged 3 to $4 \mathrm{y}$ (the same results that were obtained in the 1980s). Hunag et al. (2005) indicated that there is no critical threat of overfishing because the age composition of 2004 was almost the same as those of 1980's. The critical threat of overfishing requires additional rigorous investigations.

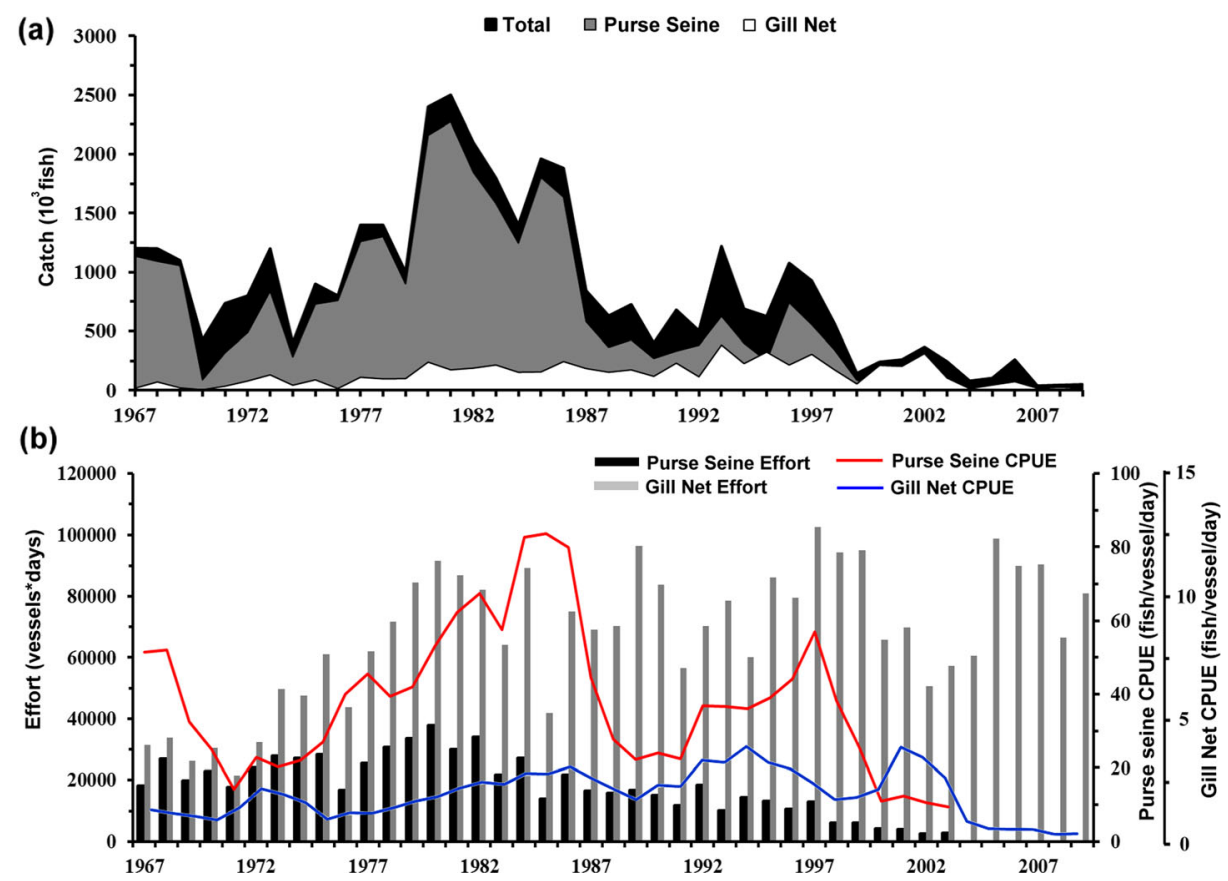

Fig. 2 Annual trends in the (a) total catch (black region) of grey mullet caught using purse seiners (grey regions) and gill nets and (b) fishing effort and CPUE of purse seiners and gill nets from 1967 to 2009 in the TS. Black bar: fishing effort of purse seiners; Grey bar: fishing effort of gill nets; Red line: CPUE of purse seiners; Blue bar: CPUE of gill nets 
Second, increasing sea surface temperatures (SSTs) and other climatic effects associated with global warming have contributed to reduce catches of grey mullet in Taiwan (Hung and Shaw 2006). Climatic effects on the fluctuations of fish populations and fisheries have long been recognized and continue to be critical (Lehodey et al. 2006; Hsieh et al. 2009; Tzeng et al. 2012a; Lan et al. 2012). The most widely studied climatic events causing impacts on fishes include those on an inter-annual scale, such as the El Niño/Southern Oscillation (ENSO) (Lehodey et al. 2006; Hsieh et al. 2009), and on a decadal scale, such as the Pacific Decadal Oscillation (PDO) (Mantua et al. 1997; Tzeng et al. 2012a). In particular, large-scale climatic oscillations such as the ENSO can cause SST changes on an inter-annual scale (Tzeng et al. 2012b; Kuo and Lee 2013). In addition, according to Belkin et al. (2009), the East China Sea is one of the most rapidly warming large marine ecosystems: its SST increased $1.22{ }^{\circ} \mathrm{C}$ from 1982 to 2006. SST is expected to increase throughout the remaining portion of the twenty-first century. Global warming changes water temperature and affects the productivity, catchability, and fishing pressure of fish species (Timmermann et al. 1999; IPCC 2007; Cheung et al. 2011; Hollowed et al. 2011).

It has been speculated that climate variability and rising SSTs caused by global warming have impacted the migration and catch rates of grey mullet; however, direct comparisons of long-term data on the migration numbers of grey mullet and climate change are scarce. It has also been speculated that rising SSTs affect the migratory stock of grey mullet and push the fishing grounds further north and further south. In this study, we analyzed long-term records of grey mullet catch rates in the TS to investigate the influence of climate changes on the annual catch rates at multiple time scales using advanced time-series analysis. Understanding these effects is an essential step toward conserving and managing this marine resource.

\section{Data and methods}

\subsection{Annual catch date of grey mullet}

Annual catch data on grey mullet in the TS from 1967 to 2009 were obtained from the Fisheries Yearbook-Taiwan area and the Fisheries Research Institute, Council of Agriculture of Taiwan. These data include both catch (number of individual fish caught) and fishery operation data (number of fishing vessels) on purse seiners and gill net fisheries in the fishing season. We also determined the number of fishing days in each fishing season. Because most of the grey mullet in the Taiwan Strait were caught by purse seiners (more than $80 \%$ ) before the early 2000s, as shown in Figure 1a, we used the catch per unit effort (CPUE) of purse seiners as a relative abundance index of grey mullet from 1967 to 2003 in our analysis. The annual CPUE was calculated as the number of fish captured per vessel on each fishing day (fish/vessel/day). We also compiled records of monthly commercial catches of 32 local fishermen's associations from 1978 to 2009 in the fishing season in the TS and show variations in the latitudinal catch percentage of grey mullet caught by Taiwanese fishing vessels.

\subsection{Environmental data}

For tropical climate signals, we investigated ENSO-related indices including the Southern Oscillation Index (SOI), Niño 3.4, and Oceanic Niño Index (ONI). Regarding the extra-tropics, 
we examined two indexes, the PDO, and Western Pacific Oscillation (WPO). We also examined solar activities (sunspot number) because some evidence suggests that solar activities may affect the Pacific climate system (Gray et al. 2010).

Schools of mature grey mullet migrate southward from the coastal waters of China along the cold NCCC to the central portion of the eastern TS in winter. Following Tzeng et al. (2012b), we used SST variations at the Chang-Yuen Rise (black dashed box in Fig. 1) was used to describe variations in the NCCC. The monthly SST data were downloaded from Simple Ocean Data Assimilation (SODA) v. 2.2.4 from 1958 to 2009 (Carton and Giese 2008). The SODA v.2.2.4 represents the first assimilation run of over 100 years and uses the $20 \mathrm{Crv} 2$ winds. The ocean model is based on the Parallel Ocean Program Version 2.0.1 numeric.

We also collected future temperature scenarios based on a subset of IPCC models that performed best in capturing historical climate variability in the North Pacific in twentieth-century hindcasts (Overland and Wang 2007). An SST model interpolated to a $1^{\circ}$ resolution with a high $\mathrm{CO}_{2}$ (A2) emissions scenario was sourced from the Geophysical Fluid Dynamics Laboratory (GFDL) CM2.0. The CM2.0 model is being applied to topics focusing on decadal-to-centennial time scale issues as well as seasonal-to-interannual problems.. Tang et al. (2008) investigated regional climate changes in Southeast China in the IPCC A2 scenario and determined that the surface air temperature will increase in the future, with a stronger trend in the winter. Based on the results reported by Lee et al. (2003), we considered latitudinal variation of the $20{ }^{\circ} \mathrm{C}$ isotherm from model output data in winter to be an indicator of the intrusion of the NCCC from 1958 to 2009.

\subsection{Long-term correlations between the catch per unit effort and climate indices}

We examined the influence of climate on the long-term variability in the annual CPUE of grey mullet caught by purse seiners, based on a regression analysis for each climate index. Because the fishing season began in the middle of November and continued to February of the following year, the CPUE during the fishing season was considered the annual catch of the year (Fig. 2b). In our study, we analyzed the autumn (before the fishing season, defined as September, October, and November) and winter (during the fishing season, defined as December, January, and February) seasons as well as the annual mean. To account for serial dependence of the time series data, the estimated generalized least squares method was used for hypothesis testing (Ives and Zhu 2006; Tzeng et al. 2012a). Because this univariate analysis was used for exploring potential climate effects, the significance level was set to $5 \%$, and values were not corrected for multiple tests. Finally, we used stepwise multivariate regression to obtain the best-fit model. The grey mullet catch data were log-transformed prior to analyses to stabilize the variance.

\subsection{Multiscale analysis of climatic forcing using a wavelet function}

Time series analyses are valuable tools for investigating long-term fluctuations in fish populations and relationships between populations and environmental variables. However, a population time series is typically noisy, exhibits nonlinear behavior, and is often strongly nonstationary (Menard et al. 2007). In this study, we used a wavelet analysis that requires no assumption of stationarity and can be used to determine the dominant modes of variability in the frequency and how these modes vary over time (Torrence and Compo 1998; Menard et al. 2007). The possible influences of particular climate patterns on the annual CPUE of grey 
mullet might not be stationary, and each climate pattern may affect the recruitment dynamics at different scales. The wavelet transformation is based on a convolution between a time series $y_{n}\left(n=0, \ldots, \mathrm{N}-1\right.$, with equal spacing $\left.\delta_{t}\right)$ and a wavelet function. Here, we used the Morlet wavelet function:

$$
\psi_{0}(\eta)=\pi^{-1 / 4} e^{i \varpi o} e^{-\eta^{2} / 2}
$$

where $\eta$ is a dimensionless time parameter, and $\omega_{0}$ is a dimensionless frequency for balancing the time and frequency localization (Torrence and Compo 1998). The wavelet transform of $y_{n}$ is

$$
W_{n}^{y}(s)=\sqrt{\frac{\delta_{t}}{s}} \sum_{n^{\prime}=1}^{N} y_{n^{\prime}} \psi_{0}\left[\left(n^{\prime}-n\right) \frac{\delta t}{s}\right]
$$

where $\mathrm{s}$ is the scale such that $\eta=$ st. Varying s causes the wavelet to stretch in time. A $5 \%$ significance level was determined based on 1000 bootstrap simulations by using spectral synthetic test (Rouyer et al. 2008). The spectral slope was obtained empirically from the timeseries data.

We then conducted cross-wavelet coherence and phase analyses to investigate relationships between climatic patterns and CPUE of grey mullet. Cross-wavelet coherence represents crosscorrelations normalized to the power of a single process, and, hence, it is not biased by the power of any single series (Grinsted et al. 2004). The cross-wavelet transformation of the two series, $X_{n}$ and $y_{n}$, is defined as $W^{X Y}=W^{X} W^{Y^{*}}$ where * denotes complex conjugation. The wavelet coherency is defined as

$$
R_{n}^{2}(s)=\frac{\left|S\left(s^{-1} W_{n}^{X Y}(s)\right)\right|^{2}}{S\left(s^{-1} W_{n}^{X}(S)\right)^{2} \cdot S\left(s^{-1} W_{n}^{Y}(S)\right)^{2}}
$$

where $\mathrm{S}$ is a smoothing operator determined according to a weighted running average in the time and scales directions. The time smoothing uses a filter given by the absolute value of the wavelet function at each scale, normalized to have a total weight of unity. By using different filter widths and shapes produces either smoother coherency or noisier coherency yet still gives the same qualitative results (Torrence and Webster 1999). The wavelet coherency phase is

$$
\varphi_{n}(S)=\tan ^{-1}\left(\frac{\operatorname{Imaginary}\left\{S\left(s^{-1} W_{n}^{X Y}(s)\right)\right\}}{\operatorname{Real}\left\{S\left(s^{-1} W_{n}^{X Y}(S)\right)\right\}}\right)
$$

Both $R_{n}^{2}(s)$ and $\phi_{n}(s)$ are functions of the time index, n, and the scale, s. Details of the mathematics and calculations can be found in Torrence and Compo (1998) and Grinsted et al. (2004).

\section{Results}

3.1 Long-term relationships between CPUE of grey mullet and climate indices

The annual CPUE of grey mullet caught using purse seines (1958-2003) (Fig. 2b, red line) exhibited variations, with a peak in the 1980s (1978 to 1987) and an apparent declining trend 
after 1990. The results of the regressions between climate indices and the CPUE of grey mullet indicated that the annual CPUEs were positively and significantly correlated with the autumn ONI, winter PDO, and annual PDO (Table 1). Winter SSTs were also correlated with the CPUE. The 1-y lagged climate effects were also tested in our analysis (not shown in Table 1), and no significant correlation were observed. The optimal model from stepwise multivariate regression analysis, including only the annual PDO, autumn ONI, and winter SSTs in the predictors, is expressed as follows: $\log _{10}(\mathrm{CPUE})=0.40 * \mathrm{PDO}+0.30 * \mathrm{SST}+0.18 * \mathrm{ONI}$ $\left(\mathrm{R}^{2}=0.503, P<0.01\right)$. These relationships suggested the abundance and migration behavior of grey mullet in the TS were affected by climate and NCCC variations, especially the annual PDO, which exhibited the strongest significant correlation $\left(R^{2}=0.82, p<0.01\right)$ with grey mullet CPUEs.

\subsection{Multi-scale variation of annual CPUE in response to climate}

The results of the cross-wavelet coherence analysis indicated the periodicity of fluctuations change CPUEs of grey mullet as well as climate indices in different periods, and indicated complex relationships and long-term correlations. The significant association of the CPUE of grey mullet was positively correlated with the annual PDO (Fig. 3a) at 4-8 y scales from

Table 1 Results of regression analysis of $\log 10$ (grey mullet catches) against climate indices

\begin{tabular}{|c|c|c|c|c|c|c|c|}
\hline Time & Factors & $n$ & Value & Beta & Std. Error & R-square & p-value \\
\hline \multirow[t]{7}{*}{ Autumn } & SST & 37.00 & 0.08 & 0.09 & 0.10 & 0.26 & 0.46 \\
\hline & SunSpot & 37.00 & 0.00 & -0.06 & 0.01 & 0.100 & 0.58 \\
\hline & ONI & 37.00 & 1.03 & 0.22 & 0.45 & 0.40 & $0.04^{\mathrm{a}}$ \\
\hline & SOI & 37.00 & 0.19 & 0.03 & 0.13 & 0.30 & 0.18 \\
\hline & Nino3.4 & 37.00 & 0.30 & -0.06 & 0.32 & 0.39 & 0.37 \\
\hline & WPO & 37.00 & -0.13 & -0.10 & 0.14 & 0.15 & 0.38 \\
\hline & PDO & 37.00 & 0.21 & -0.09 & 0.16 & 0.43 & 0.21 \\
\hline \multirow[t]{7}{*}{ Winter } & SST & 37.00 & 0.14 & 0.18 & 0.09 & 0.37 & $0.05^{*}$ \\
\hline & SunSpot & 37.00 & 0.00 & -0.08 & 0.01 & 0.12 & 0.92 \\
\hline & ONI & 37.00 & 4.07 & -0.04 & 2.57 & 0.23 & 0.14 \\
\hline & SOI & 37.00 & -0.13 & 0.01 & 0.10 & 0.29 & 0.21 \\
\hline & Nino3.4 & 37.00 & -3.78 & -0.04 & 2.59 & 0.29 & 0.17 \\
\hline & WPO & 37.00 & -0.11 & -0.16 & 0.14 & 0.17 & 0.44 \\
\hline & PDO & 37.00 & -0.36 & 0.30 & 0.15 & 0.79 & $0.03^{\mathrm{a}}$ \\
\hline \multirow[t]{7}{*}{ Annual } & SST & 37.00 & 0.00 & -0.12 & 0.00 & 0.15 & 0.26 \\
\hline & SunSpot & 37.00 & -11.63 & 0.03 & 8.24 & 0.36 & 0.19 \\
\hline & ONI & 37.00 & -0.39 & -0.07 & 0.21 & 0.38 & 0.09 \\
\hline & SOI & 37.00 & 9.29 & 0.03 & 8.23 & 0.35 & 0.28 \\
\hline & Nino3.4 & 37.00 & 9.29 & 0.03 & 8.23 & 0.35 & 0.28 \\
\hline & WPO & 37.00 & 0.10 & 0.07 & 0.23 & 0.40 & 0.67 \\
\hline & PDO & 37.00 & 0.43 & 0.39 & 0.16 & 0.82 & $0.01^{\mathrm{a}}$ \\
\hline
\end{tabular}

${ }^{\mathrm{a}} p<0.05$

ONI, Oceanic Nino Index; SOI, Southern Oscillation Index; WPO, Western Pacific Oscillation; PDO, Pacific Decadal Oscillation 
1967-1987, and at 10- to 16-y scales throughout the study period. The CPUE and winter PDO were coherent at $4-5 \mathrm{y}$ and $8-16$ y scales (Fig. $3 \mathrm{~b}$ ). The coherence of the CPUE with the autumn ONI occurred at scales of 4-6 y in 1980-1990 and 1997-2003 (Fig. 3c). We observed a coherent relationship between the winter WPO and CPUE at various scales (Fig. 3f). However, the annual sunspots and winter Niño 3.4 were not statistically significant and were out of the cone of influence (Figs. 3d, 3e). The significant coherence of the CPUE with winter SST occurred on a scale of 3-4 y in 1967-1997 and after 1997 with a possible 8-y periodicity throughout the study period (Fig. 3g) (We investigated wavelet coherence for the autumn, winter, and annual means, and observed either qualitatively similar or less clear coherence compared with those presented in Figure 3). In addition, we further investigated the correlation between the annual ONI and annual PDO with winter SSTs (Fig. 3e, $3 \mathrm{~h}$ ) and observed less clear significant coherence.

\subsection{Effects of climate change on grey mullet catches and fishing grounds}

The results of the regressions and cross-wavelet coherence analysis indicated the significant coherence of the CPUE of grey mullet with multiple climatic indexes and SSTs. The time-series trends in the annual CPUE of grey mullet caught using purse seines exhibited a high correspondence with the annual PDO (Fig. 4a, red line). Although the gill nets were not the major fishing method used before 2000, the CPUE of grey mullet caught using gill nets also exhibited a significant correspondence with the annual PDO $\left(\mathrm{R}^{2}=0.45, p<0.05\right)$. However, we also observed a declining trend in CPUE of purse seiners (Fig. 4a) and an increasing trend in winter SSTs (Fig. 4b) after

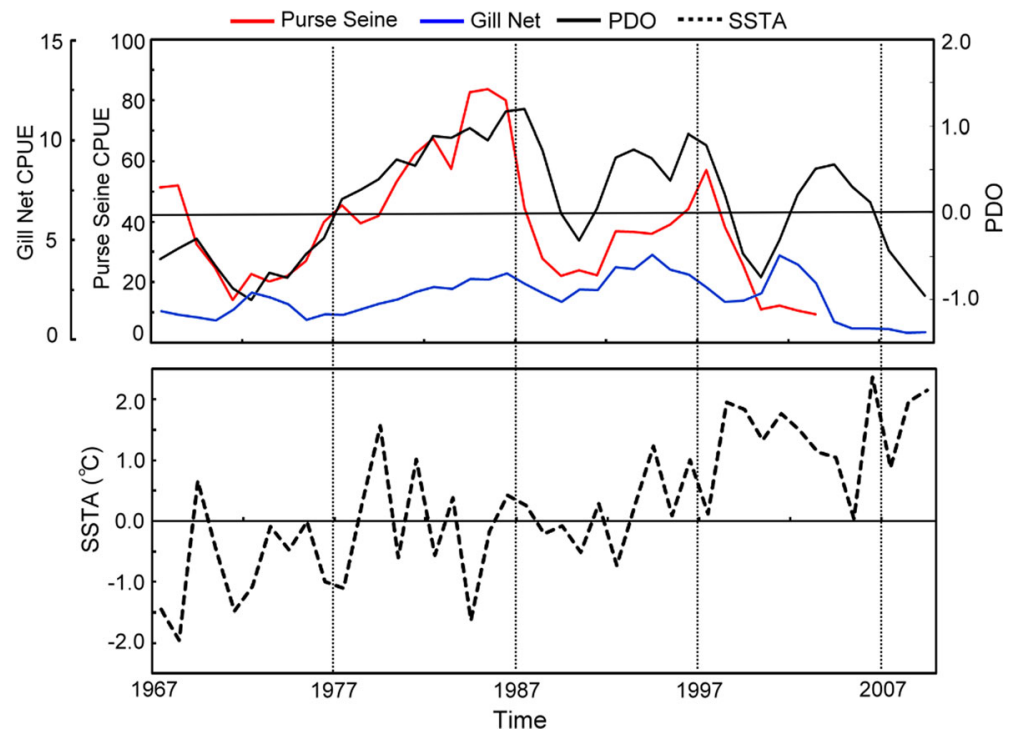

Fig. 3 Cross-wavelet coherence between climatic indices and $\log _{10}$ (CPUE of grey mullet caught using purse seiners) (a-g), and climatic indices and winter SSTs (h-i): (a) annual PDO, (b) winter PDO, (c) autumn ONI, (d) annual sunspots, (e) winter Nino 3.4, (f)winter WPO, and (g) winter SST; (h) annual PDO (i) annual ONI with winter SST. The solid-black contour encloses regions of $>95 \%$ confidence, and the black line indicates the cone of influence where edge effects become important. The phase relationship is shown by arrows, with in-phase relationships pointing to the right, out-of-phase relationships pointing to the left 

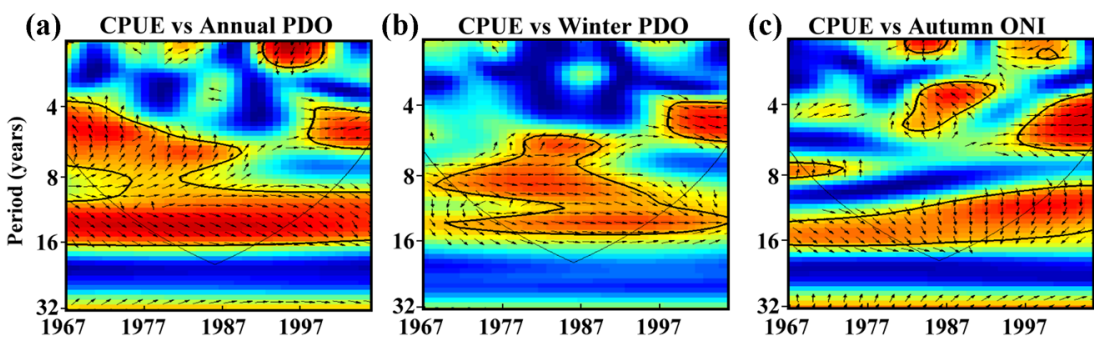

(d) CPUE vs Annual sunspots

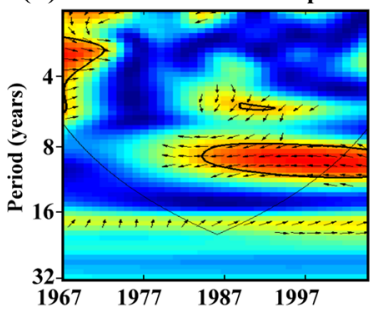

(e) CPUE vs Winter Nino 3.4
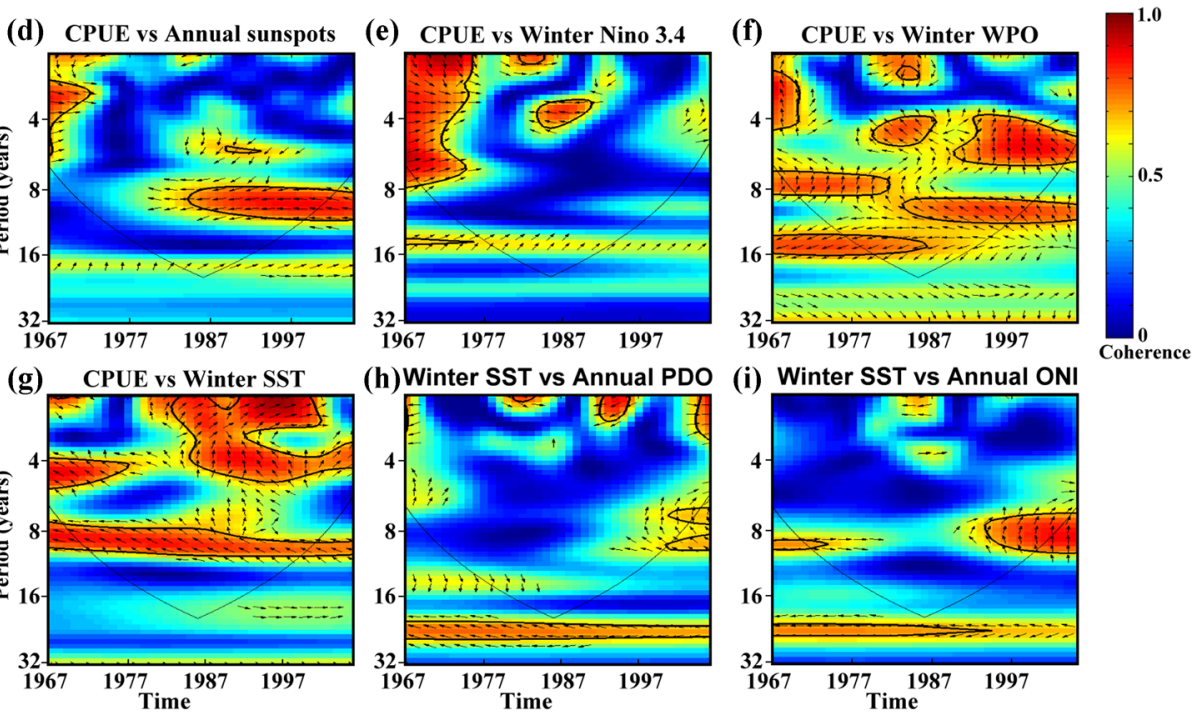

(h)Winter SST vs Annual PDO

(i) Winter SST vs Annual ONI
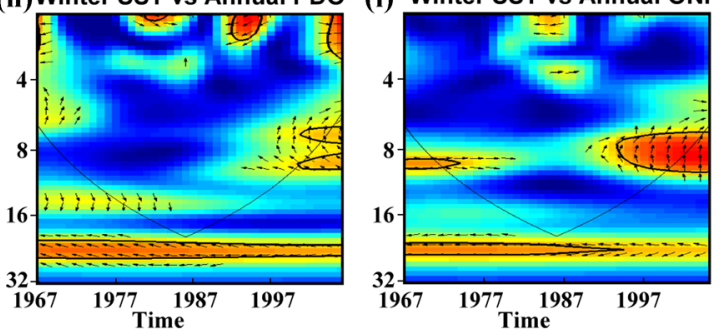

Fig. 4 Annual trends in (a) the CPUE of grey mullet caught using purse seiners (red line) and gill nets (blue line) with the PDO (black line) and (b) winter sea surface temperature anomaly (black dotted line) from 1967 to 2009

the 1980s. These results suggested that the PDO affects grey mullet migration behavior, but increased SSTs may also be a more important influence on the decreased catches of grey mullet after 1980 .

Fig. 5a shows variations in the latitudinal catch percentage of total grey mullet caught by Taiwanese fishing vessels in the TS from 1978 to 2009. These results showed that more than $85 \%$ of grey mullet were caught south of $23.5^{\circ} \mathrm{N}$ in $1978-1987$ along the TS (green line). In 1988-1997, the fishing grounds moved north, and $>30 \%$ of grey mullet were caught at latitude of $24.5^{\circ} \mathrm{N}$, which was a low-catch fishing ground in 1978-1987 (blue line). Moreover, the fishing grounds moved north of $25^{\circ} \mathrm{N}$ in $1998-2008$ (red line). To further investigate the possible reason for the northward shift in the fishing grounds, we examined the intrusion of the NCCC to the TS (Fig. 5b). In 1958-1987, the $20{ }^{\circ} \mathrm{C}$ isotherm in the TS was located between $23^{\circ} \mathrm{N}$ and $24^{\circ} \mathrm{N}$ (green line) and shifted to $23.5-24.5^{\circ} \mathrm{N}$ in 1988-1997 (blue line). The $20{ }^{\circ} \mathrm{C}$ isotherm moved north of $25^{\circ} \mathrm{N}$ in the TS after 1998 (blue line). The northerly shifts of the grey mullet fishing grounds are consistent with the latitudinal changes of the $20{ }^{\circ} \mathrm{C}$ isotherm. Finally, we examined the effects of climate change on possible displacements of the $20{ }^{\circ} \mathrm{C}$ isotherm by using the IPCC A2 scenario of SSTs in 2050 and 2075 (gray line in Fig. 5b). The scenario results showed that the $20{ }^{\circ} \mathrm{C}$ isotherm in the TS in winter is projected to move to $25.5^{\circ} \mathrm{N}$ in 2050 and to cross $26^{\circ} \mathrm{N}$ by 2075 . 

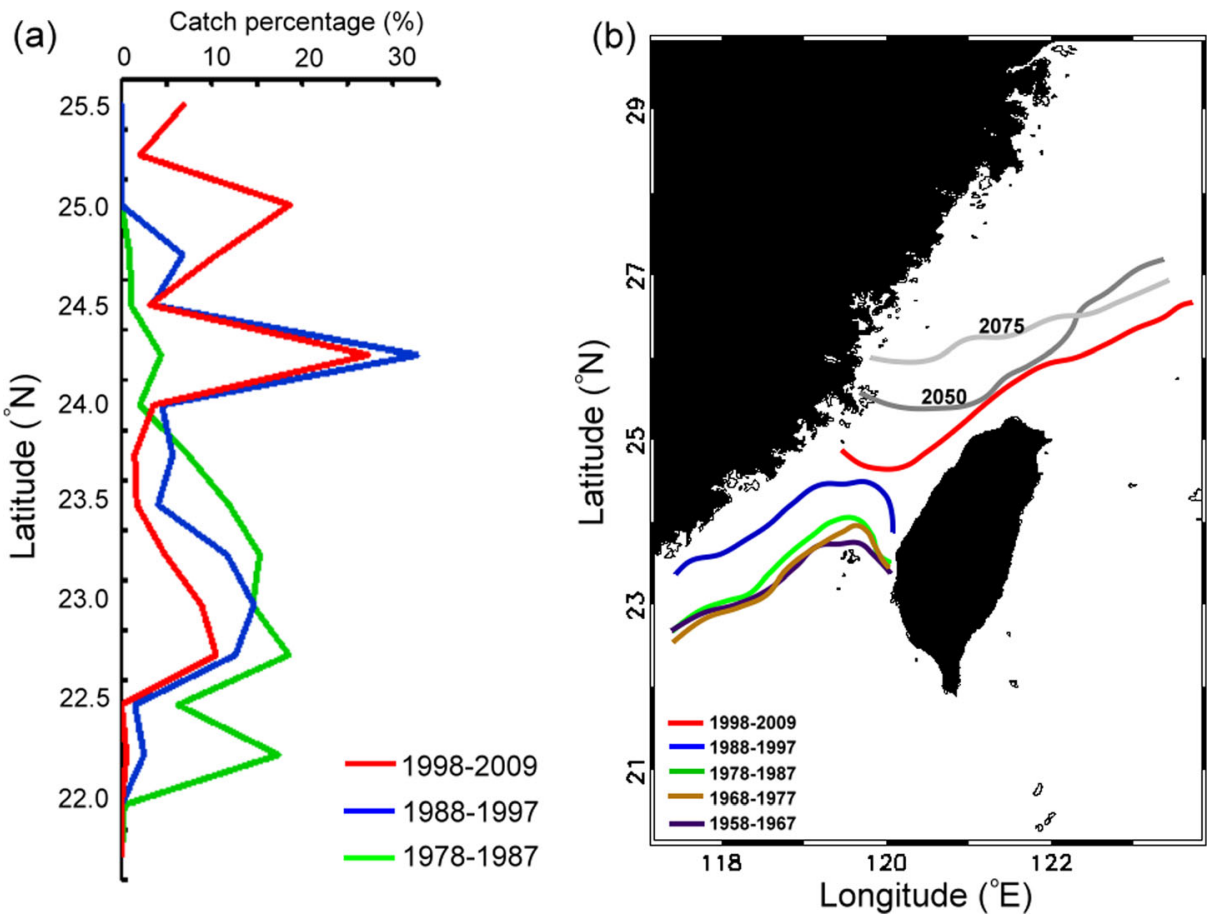

Fig. 5 (a) Latitudinal variations of the catch percentage of grey mullet caught by the Taiwanese fishing vessels on the west coast of Taiwan in 1978-1987 (green line), 1988-1997 (blue line), and 1998-2009 (red line). (b) Latitudinal variations of the $20^{\circ} \mathrm{C}$ isotherm in 1958-1967 (purple line), 1968-1977 (brown line), 1978-1987 (green line), 1988-1997 (blue line) and 1998-2009 (red line), and the IPCC A2 scenario in sea surface temperatures (SST) in 2050 and 2075 (grey lines) in Taiwan Strait in winter

\section{Discussion}

The wavelet coherence analysis showed that the CPUE of grey mullet had a significant correlation with autumn ONI at different time scales. This suggests that ENSO events may affect the abundance and migration behavior of grey mullet in the TS following the moving of NCCC in the winter. Previous studies have shown that increased northeasterly wind speeds in La Niña winters strengthened the southward-moving cold NCCC and interrupted the northward invasion of the warm South China Sea Current into the TS (Tzeng et al. 2012b). As a result, the grey mullet migrated to the TS along the cold NCCC in winter, and their distribution might have expanded to the central and southern regions of the TS, increasing their exposure to fisheries in this region. However, we found that the effects of dominant ENSO events on catches were not consistent. For example, low CPUE of purse seiners corresponded with some but not all strong El Niño events (e.g., 1986-1987 and 1997-1998 but not 1982-1983). In addition, we observed no significant coherence between the annual ONI and winter SSTs. Tzeng et al. (2012b) determined that not all El Niño/La Niña events exhibit the same correlation with SSTs in the eastern TS and suggested that other factors influence the spatial distribution of SSTs. This finding requires further supporting studies.

By contrast, we identified significant correlations of grey mullet catch rates with the annual PDO, winter PDO, and winter SSTs for periodicities of 8 to 15 years. The PDO was demonstrated to affect ocean productivity and eddy activities at the high- and mid-latitudes 
of the North Pacific (Tian et al. 2008; Tzeng et al. 2012a). Numerous studies have provided compelling evidence connecting the PDO and variations in the Pacific marine ecosystems and fisheries, such as sardine populations off the coasts of Japan, California, Chile, and Peru (Yasuda et al., 1999) and Pacific salmon catches in eastern Asia and western North America (Beamish et al., 1999). The results of our study showed that catch rates of grey mullet have increased after 1972 with the regime shift to positive PDO and showed similar fluctuations with 4 to 8-year cycles from 1967-1987. During positive PDO phases, SSTs tend to be anomalously cool in the central and western North Pacific and anomalously warm in the eastern North Pacific (Mantua et al. 1997; Mantua and Hare, 2002). Several studies found evidence for 2 full PDO cycles in the past century. Positive PDO regimes dominated in 19251946 and from 1977 to the present (Mantua and Hare, 2002). Miller et al. (1994) provided the first detailed depiction of climatic changes and considered the 1976-1977 North Pacific events a regime shift. Biologists noted dramatic late-1970s changes in much of the biota around the North Pacific and demonstrated statistically significant changes in climatic and biological variables in 1976 and 1977 (Francis and Hare, 1994).

In addition, we observed no significant coherence between the annual PDO and winter SSTs. We proposed that the correlation of grey mullet catch rates with the PDO were due to changes in the Kuroshio and NCCC geostrophic transports. During the positive PDO phase in the western North Pacific, the Aleutian low-pressure center becomes deeper and shifts to the south, and the westerlies over the North Pacific strengthen (Seager et al. 2001). This causes an increased southerly Ekman transport leading to lower SSTs at mid-latitudes. The southward shift of the zero wind stress curl eventually causes weaker Kuroshio transport during a positive PDO phase (Seager et al. 2001; Zhang et al. 2012). Previous studies have indicated that increased speeds of northeasterly winds in the winter strengthen the southward invasion of the cold NCCC and interrupt the northward movement of the warm Kuroshio Current into the TS (Tzeng et al. 2012b; Zhang et al. 2012). Distribution areas of grey mullet were pushed further to the southern TS following strengthened southward NCCC during the positive PDO phase, resulting in increased vulnerability of this species to surface fisheries in this region in winter. In addition, the extra-tropical climate patterns of the PDO probably played a critical role affecting the current transport, ocean productivity, and eddy activities, and hence the stock abundance and migration behavior of grey mullet in the TS via the NCCC in winter. Further studies should improve the detection capability demonstrated in our study.

These results suggested that the PDO plays a role in affecting grey mullet migration, but rising SST caused by global warming also decreased catch rates of grey mullet after 1980 . Climate change is likely to affect regional fisheries by raising average SSTs and increasing annual climate variability (Colbert 2000). We observed an SST anomaly based on the temporal mean SST from 1960 to 1990 at the Chang-Yuen Rise in the TS, which exhibited annual variations from 1958 to 1983 and continued to increase after 1984. The mean SST increased $1.01{ }^{\circ} \mathrm{C}$ at the Chang-Yuen Rise in the TS from $1984-2009$. The $20^{\circ} \mathrm{C}$ isotherms in the TS also shifted from $23-24^{\circ} \mathrm{N}$ in $1958-1978$ to north of $25^{\circ} \mathrm{N}$ after 1998 . These changes indicate that the strengthening of the NCCC in the TS weakened in winter because of the increased SSTs. Shen et al. (2011) indicated that the regional group of grey mullet belonging to the NCCC might provide a particularly good indicator species for global warming. Our results demonstrate that grey mullet catches exhibited a decreasing trend after 1984, and the fishing ground shifted north following the northward shift of the $20{ }^{\circ} \mathrm{C}$ isotherm. Our results also support previous studies that have indicated that the warming of surface temperatures will result in a redistribution of fishery resources. Numerous marine populations will likely migrate to higher latitudes (Colbert 2000; Mueter et al. 2009; Cheung et al. 2011). Huntingfor et al. (2013) detected significant spatial shifts in regions of differing SST variability, but observed 
less evidence of changes when the data were averaged globally. Future studies should improve the detection capability demonstrated in this study.

\subsection{Conclusions and future research}

In this study, we analyzed unique long-term records of grey mullet catch rates in the TS to investigate influences at multiple timescales climatic indices on the annual catch of grey mullet. The results indicated that certain climatic indices (ONI and PDO) and SST variations might have affected the abundance and migration behavior of grey mullet in the TS. We found that grey mullet catch rates showed fairly good correspondence with the annual PDO index. Moreover, rising SSTs in winter caused by climate change might decrease the numbers of grey mullet migrating to the TS and shift the fishing grounds to the north following changes in the $20{ }^{\circ} \mathrm{C}$ isotherm in the TS in winter.

The wavelet analysis allowed us to identify links and study the synchronies of time series, but fluctuations in grey mullet populations are probably not simply determined by any single climatic factor. Moreover, uncertainty remains, particularly regarding the impacts of changes in the productivity of the TS and the East China Sea on spawning migration and recruitment of grey mullet. The correlation between the annual WPO and winter SSTs also exhibited significant coherence (Fig. 3f). However, how climate patterns of the WPO alter the midlatitude Northwest Pacific is relatively unexplored. In addition, we also need to consider that fishing, and, more importantly, overfishing, can lead to changes of the response of an exploited population to environmental fluctuations and to the climate change (Worm and Myers 2004). Overfishing leads to increased sensitivity of fish populations to climate fluctuation and it is difficult to distinguish the effects of fishing from those of climate; oppositely, it might also just change the distribution of the population by removing parts of fishes in certain areas. We suggest that additional studies of population dynamics are necessary to clear this problem and should consider potential feedback from changes in the pelagic ecosystem. Including aspects of fishing behavior and landing data between Taiwan and Mainland China is a crucial next step in conducting more comprehensive investigations of the influence of climate variability. Finally, socioeconomic consequences must be investigated to facilitate the proposal of adaptive measures.

Acknowledgments This study was financially supported by the National Science Council, Taiwan (NSC1002621-M-019-001 and NSC100-2611-M-019-005), and the Center of Excellence for Marine Bioenvironment and Biotechnology at the National Taiwan Ocean University. We are grateful to the Fisheries Research Institute and the Council of Agriculture of Taiwan for providing us with the fishery data of grey mullet.

Open Access This article is distributed under the terms of the Creative Commons Attribution License which permits any use, distribution, and reproduction in any medium, provided the original author(s) and the source are credited.

\section{References}

Beamish RJ, Noakes D, McFarlane GA, Klyashtorin L, Ivanov VV, Kurashov V (1999) The regime concept and natural trends in the production of Pacific salmon. Can J Fish Aquat Sci 56:516-526

Belkin IM (2009) Rapid warming of Large Marine Ecosystems. Prog Oceanogr 81:207-213 
Carton JA, Giese B (2008) A reanalysis of ocean climate using simple ocean data assimilation (SODA). Mon Weather Rev 136:2999-3017

Cheung WWL, Dunne J, Sarmiento JL, Pauly D (2011) Integrating ecophysiology and plankton dynamics into projected maximum fisheries catch potential under climate change in the Northeast Atlantic. ICES J Mar Sci 68(6):1008-1018

Colbert D (2000) Cities, Seas, and Storms: Managing Change in Pacific Island Economies. Vol II Managing Pacific Towns. Washington, D.C

Francis RC, Hare SR (1994) Decadal-scale regime shifts in the large marine ecosystems of the North-east Pacific: a case for historical science. Fish Oceanogr 3(4):279-291

Gray LJ, Beer J, Geller M, Haigh JD, Lockwood M et al (2010) Solar influences on climate. Rev Geophys 48:53

Grinsted A, Moore JC, Jeverejeva S (2004) Application of the cross wavelet transform and wavelet coherence to geophysical time series. Nonlinear Process Geophys 11:561-566

Hollowed AB, Barange M, Ito S, Kim S, Loend H, Peck MA (2011) Effects of climate change on fish and fisheries: forecasting impacts, assessing ecosystem responses, and evaluating management strategies. ICES J Mar Sci 68(6):984-985

Hsieh CH, Chen CH, Chiu TS, Lee KT, Shieh FJ, Pan JY, Lee MA (2009) Time series analyses reveal transient relationships between abundance of larval anchovy and environmental variables in the coastal waters southwest of Taiwan. Fish Oceanogr 18(2):102-117

Huang CS, Lin JC, Huang JJ (2005) Investigation and Surveillance of Grey Mullet Resource. FRI Newsletter 9:1-5

Huang CS, Su WC (1986) Analysis on the fishing condition of grey mullet in Taiwan. In:Su, W.C. (ed) Study on the resource of grey mullet in Taiwan (1963-1985) Taiwan Fisheries Research Institute. Keelung, Taiwan, pp 35-48

Hung CM, Shaw D (2006) The impact of upstream catch and global warming on the grey mullet fishery in Taiwan: a non-cooperative game analysis. Mar Resour Econ 21:285-300

Huntingford C, Jones PD, Livina VN, Lenton TM, Cox, PM (2013) No increase in global temperature variability despite changing regional patterns. Nature 12310: doi:10.1038.

IPCC (2007) Summary for policymakers. In Climate Change 2007: the Physical Science Basis. Contribution of Working Group I to the Fourth Assessment Report of the Intergovernmental Panel of Climate Change, pp. 1-18. Ed. by Solomon S, Qin D, Manning M, Chen Z, Marquis M, Averyt KB, Tignor M et al. Cambridge University Press, Cambridge, UK. 1008 pp.

Ives AR, Zhu J (2006) Statistics for correlated data: Phylogenies, space, and time. Ecol Appl 16:20-32

Kuo YC, Lee MA (2013) Decadal variation of wintertime sea surface temperature in the Taiwan Strait. J Mar Sci Technol Taiwan 21 doi: 10.6119/JMST-013-1219-9 (in press).

Lan KW, Evans K, Lee MA (2012) Effects of climate variability on the distribution and fishing conditions of yellowfin tuna (Thunnus albacares) in the western Indian Ocean. Clim Change 115(3-4) doi:10.1007/ s10584-012-0637-8

Lee MA, Yeah CD, Cheng CH, Chan JW, Lee KT (2003) Empirical orthogonal function analysis of AVHRR sea surface temperature patterns in Taiwan Strait. J Mar Sci Technol 11(1):1-7

Lehodey P, Alheit J, Barange M, Baumgartner T, Beaugrand G et al (2006) Climate variability, fish, and fisheries. J Clim 19:5009-5030

Mantua NJ, Hare SR (2002) The Pacific Decadal Oscillation. J Oceanogr 58:35-44

Mantua NJ, Hare SR, Zhang Y, Wallace JM, Francis RC (1997) A Pacific interdecadal climate oscillation with impacts on salmon production. Bull Am Meteorol Soc 78:1069-1079

Menard F, Marsac F, Bellier E, Cazelles B (2007) Climatic oscillations and tuna catch rates in the Indian Ocean: a wavelet approach of time series analysis. Fish Oceanogr 16:95-104

Miller AJ, Cayan DR, Barnett TP, Graham NE, Oberhuber JM (1994) The 1976-77 climate shift of the Pacific Ocean. Oceanography 7:21-26

Mueter FJ, Broms C, Drinkwater KE, Friedland KD, Hare JA, Hunt GL, Melle W, Taylor M (2009) Ecosystem responses to recent oceanographic variability in high-latitude Northern Hemisphere ecosystems. Prog Oceanogr 81:317-325

Overland JE, Wang M (2007) Future climate of the north Pacific Ocean. Eos Trans Amer Geophys Union 88(16): 178

Rouyer T, Fromentin JM, Stenseth NC, Cazelles B (2008) Analysing multiple time series and extending significance testing in wavelet analysis. Mar Ecol Prog Ser 359:11-23. doi:10.1029/ 96jc03549

Seager R, Kushnir Y, Naik NH, Cane MA, Miller J (2001) Wind-driven shifts in the latitude of the Kuroshio-Oyashio extension and generation of SST anomalies on decadal timescales. J Clim 14:4249-4265

Shen KN, Jamandre BW, Hsu CC, Tzeng WN, Durand JD (2011) Plio-Pleistocene sea level and temperature fluctuations in the northwestern Pacific promoted speciation in the globally-distributed flathead mullet Mugil cephalus. BMC Evol Biol 11:83. doi:10.1186/1471-2148-11-83 
Thomson JM (1963) Synopsis of biological data on the grey mullet Mugil cephalus Linnaeus 1758. CSIRO Div FishOceanogr 1:1-14

Tang JP, Chen X, Zhao M, Su BK (2008) Numerical simulation of regional climate change under IPCC A2 scenario in China. Acta Meteorol Sin 66:13-25

Tian Y, Kidokoro H, Watanabe T, Iguchi N (2008) The late 1980s regime shift in the ecosystem of Tsushima Warm Current in the Japan/East Sea: evidence from historical data and possible mechanisms. Prog Oceanogr $77: 127-145$

Timmermann A, Oberhrber J, Bacher A, Esch M, Latif M, Roeckner E (1999) Increased El Niño frequency in a climate model forced by future greenhouse warming. Nature 198:694-697

Torrence C, Compo GP (1998) A practical guide to wavelet analysis. Bull Am Meteorol Soc 79:61-78

Torrence C, Webster PJ (1999) Interdecadal changes in the ENSO-monsoon system. J Clim 12:2679-2690

Tung IH (1981) On the fishery biology of gray mullet, Mugil cephalus L., in Taiwan. Affairs of National Taiwan University Report of the Institute of Fishery Biology of Ministry of Economic Affairs and National Taiwan University 3:38-102

Tzeng WN, Tseng YH, Han YS, Hsu CC, Chang CW, Di Lorenzo E, Hsieh CH (2012a) Evaluation of multiscale climate effects on annual recruitment levels of the Japanese Eel, Anguilla japonica, to Taiwan. PLoS ONE 7(2):e30805

Tzeng MT, Lan KW, Chan JW (2012b) Interannual variability of wintertime sea surface temperatures in the eastern Taiwan Strait. J Mar Sci Technol Taiwan 20(6):707-712

Worm B, Myers RA (2004) Managing fisheries in a changing climate. Nature 429:15

Yasuda I, Sugusaki H, Watanabe Y, Minobe S, Oozeki Y (1999) Interdecadal variations in Japanese sardine and ocean/climate. Fish Oceanogr 8:18-24

Zhang Q, Hou Y, Yan T (2012) Inter-annual and inter-decadal variability of Kuroshio heat transport in the East China Sea. Int J Climatol 32(4):481-488 